Original Article

\title{
Serum Leptin and Bone Mineral Density in Hemodialysis Patients with or without Liver Diseases
}

\author{
Tarek A Ghonemy*, Ebrahim M Salim, Marwan Atia, Ahmed Fekry, Khalid Shawky \\ Faculty of Medicine, Zagazig University, Egypt
}

\begin{abstract}
Introduction: Leptin is a hormone secreted by adipocytes that plays an important role in regulating appetite and energy expenditure. Our aim was to evaluate serum leptin level in hemodialysis (HD) patients with or without chronic liver disease (CLD) and study the relationship between serum leptin level and bone mineral density in these groups of patients.
\end{abstract}

Methods: we recruited 20 healthy volunteers as controls (group I), 20 patients on regular HD with normal liver function (group II), 20 CLD patients with normal kidney function (group III) and 20 patients on regular HD with CLD (group IV). We measured serum calcium, phosphorus, parathyroid hormone (PTH), total alkaline phosphatase (ALP), serum leptin, 24-hours urinary hydroxyproline and bone mineral density (BMD) of the lumber spine and femoral neck by DEXA scan.

Results: Serum leptin level was significantly higher $(\mathrm{P}<0.001)$ in HD patients and CLD patients compared to controls. Its level was also significantly elevated in HD patients without liver disease (group II) compared to patients with CLD who had no renal failure (group III). Urinary hydroxyproline level was increased in both HD patients and CLD patients. We detected a positive correlation between serum leptin level and urinary hydroxyproline in all patient groups. There was a significant decrease in BMD in HD and CLD patients. BMD was significantly lower in HD patients without CLD compared to HD patients with CLD. There was a significant negative correlation between serum leptin level and BMD in CLD patients without renal disease but not in other groups $(\mathrm{r}=-0.6, \mathrm{P}=0.01)$.

Conclusion: Serum leptin is elevated in HD patients with or without liver disease and in CLD patients. Serum leptin level is inversely correlated with BMD in CLD patients without renal disease.

\footnotetext{
* Corresponding Author; Faculty of Medicine, Zagazig University, Egypt; E mail: tarekghonemy@hotmail.com
}

Keywords: Bone Mineral Density; Cirrhosis; Chronic Liver Disease; Hemodialysis; Leptin

\section{The authors declared no conflict of interest}

\section{Introduction}

Leptin is a cytokine protein encoded by the ob gene and secreted from adipose tissue [1]. Circulating levels have been shown to be positively related to fat mass in both lean and obese individuals [2]. Leptin first emerged as a component of a regulatory loop linking fat mass to food intake and energy expenditure [3]. Peripherally, leptin is thought to exert positive effects on bone formation, while it has negative central effects on bone formation via specific receptors located on the hypothalamic nuclei [4].

Despite a preliminary understanding of leptin-skeletal interactions, the exact roles of leptin in bone metabolism have not yet been clarified. In vitro, leptin has been shown to exert direct osteotrophic effects by promoting differentiation of bone marrow stromal cells into osteoblasts [5] and by inhibiting osteoclast generation [6]. These data have been confirmed in different animal models, with peripheral leptin administration having positive effects on bone by modulating formation and resorption processes [7]. However, studies in humans have not been able to confirm these actions [8].

Leptin levels are increased in patients with end-stage renal disease (ESRD) [9]. Patients treated by peritoneal dialysis (PD) seem to have higher leptin levels compared to patients treated by hemodialysis (HD). This could be the effect of a marked increase in body fat mass as a consequence of the continuous carbohydrate load [9]. It has been speculated that hyperleptinemia may contribute to uremic anorexia and malnutrition [10].

Liver cirrhosis is a debilitating chronic disease associated with severe complications and high mortality. Hepatic osteodystrophy with consequent osteoporosis and increased risk of bone fracture represent some of the 
more recently investigated complications. Initial studies focused on osteoporosis in patients with primary biliary cirrhosis. Recently, however, it has been shown that liver cirrhosis is a risk factor for osteoporosis and bone fractures independent of its etiology [11].

\section{Methods}

This work was carried out in the departments of Internal Medicine, Medical Biochemistry and Diagnostic Radiology, Faculty of Medicine, Zagazig University in the period from June 2006 to January 2009. We recruited 40 patients with ESRD, 20 patients suffering from chronic liver disease (CLD) and 20 apparently healthy subjects. Exclusion criteria were:

1. Age above 60 years.

2. Menopause for females.

3. Thyroid dysfunction.

4. Obesity, defined by body mass index (BMI) $\geq 30$ $\mathrm{kg} / \mathrm{m}^{2}$ [12].

5. Hepatic neoplasm or other malignancy.

6. Obstructive jaundice.

7. Diabetes mellitus.

8. Drugs that affect mineral metabolism (corticosteroids, cytotoxic drugs, estrogen or testosterone) in the past six months.

Subjects were classified into four groups as follows:

Group I: Included 20 apparently healthy subjects (12 males and 8 females) as a control group. Their age ranged from 22 to 47 years, with a mean \pm SD of $47.4 \pm 6.2$ years. All were clinically normal and had normal hematological and biochemical profiles.

Group II: Included 20 ESRD patients (13 males and 7 females) on regular hemodialysis with no liver disease. Their minimum duration on dialysis was one year. Their age ranged from 22 to 48 years, with a mean \pm SD of 39.3 \pm 6.3 years.

Group III: Included 20 CLD patients (9 males and 11 females) without kidney disease. Their age ranged from 28 to 49 years, with a mean \pm SD of $38 \pm 6$ years. Nine patients had HCV infection, seven had HBV infection and four had both schistosomiasis and HCV infection. Shistomsomiasis was diagnosed by stool analysis or rectal snip for schistosoma ova. Group III patients were divided into 3 subgroups according to Child-Pugh classification: Child A ( 9 cases), Child B (5 cases) and Child C (6 cases).

Group IV: Included 20 ESRD patients (10 males and 10 females) on regular HD for more than one year who also suffered from CLD. Their age ranged from 22 to 44 years, with mean \pm SD of $36.4 \pm 5.2$ years. Eight patients had
HCV infection, six had HBV infection, three had chronic schistosomiasis and three had both chronic schistosomiasis and HCV infection. They were divided into 3 subgroups according to Child-Pugh classifications: Child A (8 cases), Child B (7 cases) and Child C (5 cases).

All patients of group II and III received 12 hours of HD weekly divided into 3 sessions by Fresenius 4008B machine, using "hemophane" membranes with surface area adjusted to every patient. Group II patients were dialyzed using acetate dialysis solutions $(\mathrm{Na}=135-145$, $\mathrm{K}=0-4, \mathrm{Ca}=2.5-3.5, \mathrm{Mg}=0.5-1$, chloride $=100-119$, acetate $=35-38$ and dextrose $=11 \mathrm{mEq} / \mathrm{l}$ ). Group IV patients were dialyzed using bicarbonate dialysis solutions $(\mathrm{Na}=135-145, \mathrm{~K}=0-4, \mathrm{Ca}=2.5-3.5, \mathrm{Mg}=$ $0.5-1$, chloride $=100-124$, acetate $=2-4$, dextrose $=11$, and bicarbonate $=30-38 \mathrm{mEq} / \mathrm{l})$. All patients of group II and IV were prescribed calcium carbonate $1500 \mathrm{mg} /$ day and one-alpha-calcidol $0.25 \mathrm{mcg} /$ day.

All patients were interviewed for clinical history and examination. General investigations included: complete blood count, blood sugar, urine and stool analysis, total and direct bilirubin levels, liver enzymes, serum total proteins, serum albumin level, albumin/globulin ratio, prothrombin time, serum alkaline phosphatase, blood urea level and serum creatinine level. All tests were done using Hitachi 902 automatic analyzer. Abdominal ultrasound was done for all subjects. Viral hepatitis markers were detected by 3rd generation ELISA and confirmed by PCR. Specific investigations were done for all subjects, including:

1. Serum calcium level by colorimetric method; using automatic photometer (Behring- ELISA).

2. Serum phosphorus level by colorimetric method; using automatic photometer (Behring- ELISA).

3. Assay of human intact parathyroid hormone.

4. Estimation of serum leptin (BIOSOURCE LEPTIN EASIA)

5. Determination of urinary hydroxyproline.

6. Bone density measurement by DEXA scan (Norland Radiation) on lumbar spine (LS) and femoral neck (FN).

$10 \mathrm{ml}$ of venous blood was collected from each patient before dialysis in groups II, IV and in the early morning (9AM) in groups I and III. The blood was allowed to clot and centrifugation and separation of serum were performed within 2 hours. The specimen was then divided into two tubes. One tube was used for routine investigations that were performed immediately. The other tube was labelled and stored at $-20^{\circ} \mathrm{c}$ until completion of the study and transported frozen on ice to relevant laboratories for calcium, phosphorus and leptin determination. 
Table 1: Laboratory data of the studied groups

\begin{tabular}{|c|c|c|c|c|c|}
\hline & Group I & Group II & Group III & Group IV & $\mathbf{P}$ \\
\hline Total calcium (mg/dl) & $9.5 \pm 0.6$ & $7.3 \pm 0.6$ & $7.9 \pm 0.7$ & $7.4 \pm 0.34$ & 0.001 \\
\hline Corrected calcium (mg/dl) & $9.38 \pm 0.7$ & $7.47 \pm 0.8$ & $8.85 \pm 0.54$ & $8.13 \pm 0.56$ & 0.001 \\
\hline Phosphorus (mg/dl) & $4.1 \pm 0.37$ & $6.6 \pm 1.36$ & $4.455 \pm 0.6$ & $5.6 \pm 1.5$ & 0.001 \\
\hline PTH (pg/ml) & $34.0 \pm 12.3$ & $124.7 \pm 59$ & $42.8 \pm 19.4$ & $111.7 \pm 53.2$ & 0.001 \\
\hline Serum leptin (ng/ml) & $3.9 \pm 0.98$ & $15.07 \pm 3.0$ & $9.6 \pm 3.9$ & $12.4 \pm 3.6$ & 0.001 \\
\hline Urinary hydroxyproline (mg/24 hr) & $13.2 \pm 4.5$ & $56.5 \pm 17.6$ & $40.5 \pm 16.3$ & $44.7 \pm 16.6$ & 0.001 \\
\hline
\end{tabular}

Table 2: Bone density measured by DEXA t-score $(\mathrm{g} / \mathrm{cm} 2)$ at lumbar spine and formal neck among studied groups

\begin{tabular}{llllll}
\hline & Group I & Group II & Group III & Group IV & P \\
\hline Lumbar Spine $\left(\mathrm{g} / \mathrm{cm}^{2}\right)$ & $-0.01 \pm 0.65$ & $-2.2 \pm 0.85$ & $-1.3 \pm 0.44$ & $-1.53 \pm 0.55$ & 0.001 \\
Formal Neck $\left(\mathrm{g} / \mathrm{cm}^{2}\right)$ & $-0.03 \pm 0.52$ & $-3.36 \pm 0.58$ & $-1.4 \pm 0.47$ & $-1.5 \pm 0.5$ & 0.001 \\
Urinary hydroxyproline $(\mathrm{mg} / 24 \mathrm{hr})$ & $13.2 \pm 4.5$ & $56.5 \pm 17.6$ & $40.5 \pm 16.3$ & $44.7 \pm 16.6$ & 0.001 \\
\hline
\end{tabular}

The following statistical methods were used for analysis and summarization of results: arithmetic mean, standard deviation (SD), analysis of variance (ANOVA or Ftest), least significance difference (LSD) and correlation coefficient (r) [13].

\section{Results}

The laboratory data of the studied groups are shown (Table 1). There were highly significant differences between groupsintotaland correctedcalcium, parathyroidhormone, serum leptin and 24-hour urinary hydroxyproline levels. Serum leptin and urinary hydroxyproline were higher in HD patients compared to the other groups. Table- 2 shows that BMD at the level of lumbar spine and femoral neck was significantly decreased in all groups in comparison to controls. Difference was particularly evident between the group of ESRD without liver disease and the two other groups.

Figure-1 shows lack of significant correlation between leptin level and BMD at the level of lumbar spine in group II $(r=-0.2, P=0.3)$. Figure- 2 shows the inverse correlation between leptin level and BMD at the level of lumbar spine in group III $(r=-0.6, \mathrm{P}<0.01)$. Figure-3 shows lack of significant correlation between leptin level and BMD at the level of lumbar spine in group IV $(\mathrm{r}=0.2, \mathrm{P}=0.4)$.

\section{Discussion}

Leptin is a hormone secreted by adipocytes that plays an important role in regulating appetite and energy expenditure. It is also involved in the function of other systems, including the neuroendocrine, hematopoietic and immune systems [14]. Human studies have yielded conflicting data concerning the relationship between bone mineral density (BMD) and leptin. Some studies have reported a weak positive correlation [15] or a negative correlation between serum leptin levels and BMD [16], whereas other studies have noted no association between leptin and BMD [17]. Renal osteodystrophy (ROD) is a common complication of chronic renal failure (CRF). The Egyptian renal data system showed the prevalence of ROD to be $33.3 \%$ among dialysis patients [18]. Osteodystrophy is an important complication of chronic liver diseases (CLD) which includes both osteoporosis and osteomalacia. Both conditions are associated with significant morbidity through fractures, resulting in pain, deformity and immobility. This study was designed to evaluate serum leptin level in ESRD patients undergoing regular HD with or without liver disease. We aimed to evaluate the relationship between serum leptin level and bone mineral density in these groups of patients. The reduction in serum calcium among all patients groups as compared to the control group is similar to the results reported by Shenouda et al [19]. The hypocalcemia in CRF could be due to phosphorus retention, decreased calcitrol and skeletal resistance to the calcemic action of PTH. Elevated intact parathyroid hormone (PTH) among patients maintained on regular HD (group II and IV) may be explained by secondary hyperparathyroidism. It occurs early in the course of CRF mainly because of decreased calcitriol level, low serum calcium level and phosphorus retention [20]. 
Figure 1: Correlation between serum leptin $(\mathrm{ng} / \mathrm{ml})$ and the DEXA t-score of bone mineral density at the lumbar spine $\left(\mathrm{g} / \mathrm{cm}^{2}\right)$ in group II

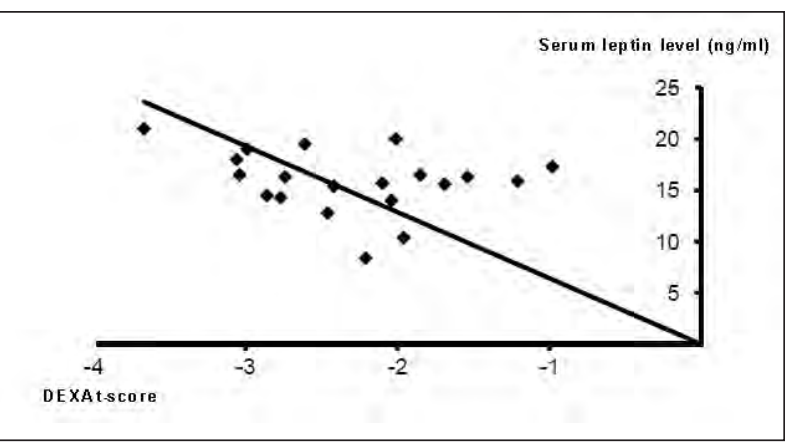

Figure 2: Correlation between serum leptin $(\mathrm{ng} / \mathrm{ml})$ and the DEXA $t$-score of bone mineral density at the lumbar spine $\left(\mathrm{g} / \mathrm{cm}^{2}\right)$ in group III

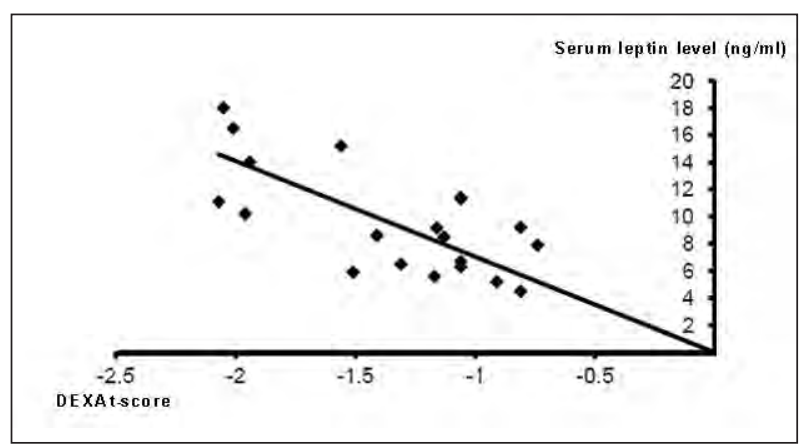

Figure 3: Correlation between serum leptin $(\mathrm{ng} / \mathrm{ml})$ and the DEXA t-score of bone mineral density at the lumbar spine $\left(\mathrm{g} / \mathrm{cm}^{2}\right)$ in group IV

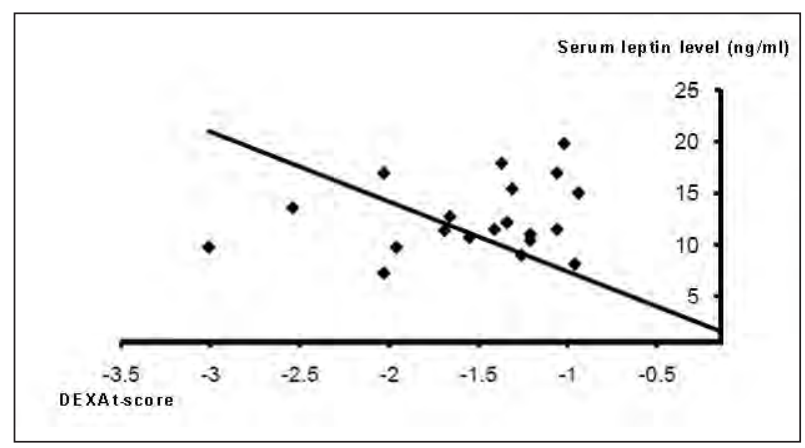

Inthis study, urinary hydroxyprolinelevelwas significantly higher in all patient groups (II, III and IV) compared to controls. Its level was significantly higher in HD patients without CLD (group II) compared to cirrhotic non uremic patients (group III). Elevated urinary hydroxyproline in ESRD patients indicates high bone turnover rate and high resorption of bone matrix, and concurs with the result obtained by Zoccali et al [21]. The increased level of urinary hydroxyproline in CLD patients was probably caused by active hepatic fibrogenesis and collagen remodelling in the diseased liver. This result agrees with the results obtained by Schiefke et al [22] as they have observed that urinary excretion of hydroxyproline was abnormally high in patients with liver cirrhosis.

In the present study, there was a highly significant increase in serum leptin levels in all patient groups (II, III and IV) compared to control group. Elevated serum leptin level in CRF patients could be attributed to the reduced filtering ability of the kidney, causing leptin to accumulate in the serum [17, 23]. After renal transplantation the level of serum leptin falls. Elevated serum leptin level in CLD patients could be due to the inflammation induced by chronic viral hepatitis. Inflammatory mediators such as interlukin-1 (IL1) and tumour necrosis factor- $\alpha$ (TNF- $\alpha$ ) stimulate leptin secretion [24]. Leptin may also have a role in the progression of hepatic fibrosis. Firstly, leptin increases the production of transforming growth factor- $\beta$ (TGF- $\beta$ ), a potent profibrogenic cytokine which upregulates the production of extra cellular matrix from hepatic stellate cells (HSC) [25]. Secondly, elevated leptin levels may promote hepatic steatosis and steatohepatitis [26].

We found a highly significant decrease in BMD in all patient groups (II, III and IV) compared to controls. BMD was also significantly lower in HD patients without CLD (group II) compared to HD patients with CLD (group IV). The reduction in BMD among HD patients could be attributed to ROD, secondary hyperparathyroidism, adynamic bone disease or osteomalacia. Barnas et al [27] reported that skeletal changes are initiated at the early stages of CRF as estimated from reduced BMD due to high turnover bone loss.

Patients with ESRD and normal liver function (group II) displayed the typical profile of hypocalcemia, hyperphosphatemia, increased total ALP, high PTH, increased urinary hydroxyproline and decreased BMD. This is a cascade of metabolic and structural consequences following impairment of one-alpha hydroxylation and the influence of hyperphosphatemia which reflects the reduction in GFR. This leads to impaired calcium absorption, hypocalcemia, secondary hyperparathyroidism and increased bone turnover [28].

The reduction in BMD in CLD patients (groups III and IV) is most properly due to malnutrition, calcium malabsorption, immobilization and cholestasis. Hyperbilirubinemia inhibits osteoblast proliferation and decreases bone formation. Decreased BMD in CLD patients could also be due to hypogonadism, deficiency of vitamin D, treatment with glucocorticoids, and alcohol consumption [29].

In the present study, the prevalence of osteoporosis according to BMD measured by DEXA was significantly higher among HD patients without CLD (group II) 
compared to ESRD patients with CLD (40\% versus $10 \%$ at lumbar spine and $55 \%$ versus $5 \%$ at femoral neck). This suggests that cirrhosis modified the typical renal failure profile of ROD by decreasing high turnover bone loss and dialysis associated osteopenia and agrees with the result obtained by Shenouda et al [19].

In this study, there was no significant correlation between serum leptin level and BMD in ESRD patients. This contrasts with the findings obtained by Morberge et al [16], who reported that leptin inhibits bone formation. It also contrasts with the results reported by Ghazali et al [30] who found a positive correlation between serum leptin levels and BMD in HD patients, suggesting that leptin stimulates the bone formation.

We found a significant inverse relationship between serum leptin level and BMD in CLD patients This result is consistent with the results reported by Ormasdottir et al [31] who postulated that the central (inhibitory) effect of leptin predominates over its the peripheral (stimulatory) effect, contributing to the reduced bone formation in CLD patients. Steppan et al [14] demonstrated that peripheral administration of leptin to leptin-deficient ob/ ob mice stimulates bone growth and increases cortical bone formation considerably more than control groups. However, infusion of leptin into the cerebral ventricles caused bone loss in both leptin deficient and the wild type mice [32].

Caro et al [33] postulated that $25 \mathrm{ng} / \mathrm{ml}$ is the threshold above which leptin concentration in the cerebrospinal fluid (CSF) ceases to increase in correlation with serum level. Below that threshold, the centrally negative effects of leptin on BMD override the peripherally bone sparing effects [34]. Above that threshold there is no further increase in CSF leptin and no increase in its central inhibitory effects, but the positive peripheral effects of leptin continue to increase. That may explain the increased BMD among HD patients reported by Ghazali et al [30], as their patients serum leptin levels exceeded $25 \mathrm{ng} / \mathrm{dl}$. The positive correlation between serum leptin level and urinary hydroxyproline in all patient groups indicates a high rate of bone resorption. This agrees with the results obtained by Iwamoto et al [35] who found a positive correlation between serum leptin and bone resorption markers in pre-menopausal women.

\section{Conclusion}

From these observations, we can conclude that serum leptin level is elevated in ESRD patients treated with regular HD as well as CLD patients. The elevation of serum leptin is inversely correlated with BMD in CLD patients without liver disease, but not in other patient groups.

\section{References}

1. Zhang F, Chen Y, Heiman M, Dimarchi R. Leptin: structure, function and biology. Vitam Horm. 2005;71:345-72.

2. Hickey MS, Considine RV, Israel RG, Mahar TL, McCammon MR, Tyndall GL, Houmard JA, Caro JF. Leptin is related to body fat content in male distance runners. Am J Physiol. 1996 Nov;271(5 Pt 1):E938-40.

3. Halaas JL, Gajiwala KS, Maffei M, Cohen SL, Chait BT, Rabinowitz D, Lallone RL, Burley SK, Friedman JM. Weight-reducing effects of the plasma protein encoded by the obese gene. Science. 1995 Jul 28;269(5223):543-6.

4. Karsenty G. Leptin controls bone formation through a hypothalamic relay. Recent Prog Horm Res. 2001;56:40115.

5. Thomas T, Gori F, Khosla S, Jensen MD, Burguera B, Riggs BL. Leptin acts on human marrow stromal cells to enhance differentiation to osteoblasts and to inhibit differentiation to adipocytes. Endocrinology. 1999 Apr;140(4):1630-8.

6. Holloway WR, Collier FM, Aitken CJ, Myers DE, Hodge JM, Malakellis M, Gough TJ, Collier GR, Nicholson GC. Leptin inhibits osteoclast generation. J Bone Miner Res. 2002 Feb;17(2):200-9.

7. Martin A, de Vittoris R, David V, Moraes R, Bégeot M, Lafage-Proust MH, Alexandre C, Vico L, Thomas T. Leptin modulates both resorption and formation while preventing disuse-induced bone loss in tail-suspended female rats. Endocrinology. 2005 Aug;146(8):3652-9.

8. Karsenty G. Convergence between bone and energy homeostases: leptin regulation of bone mass. Cell Metab. 2006 Nov;4(5):341-8.

9. Stenvinkel P. Leptin and its clinical implications in chronic renal failure. Miner Electrolyte Metab. 1999 JulDec;25(4-6):298-302.

10. Bossola M, Muscaritoli M, Tazza L, Panocchia N, Liberatori M, Giungi S, Tortorelli A, Rossi Fanelli F, Luciani G. Variables associated with reduced dietary intake in hemodialysis patients.J Ren Nutr. 2005 Apr;15(2):244-52.

11. Cijevschi C, Mihai C, Zbranca E, Gogalniceanu P. Osteoporosis in liver cirrhosis. Rom J Gastroenterol. 2005 Dec;14(4):337-41.

12. WHO Consultation on Obesity. Obesity: preventing and monitoring the global epidemic. Geneva: World Health Organization; 2000. p. 276. (WHO technical report series; 894). Available from:http://whqlibdoc.who. int/trs/WHO_TRS_894.pdf.

13. Dean A, Dean J and Brendle K. Epi-Info version 6.02: a word processing, data base and statistics program for ecology microcomputers. Atlanta (GA): Center for Disease Control and Prevention; 2000. 
14. Steppan CM, Crawford DT, Chidsey-Frink KL, Ke H, Swick AG. Leptin is a potent stimulator of bone growth in ob/ob mice Regul Pept. 2000 Aug 25;92(1-3):73-8.

15. Yamauchi M, Sugimoto T, Yamaguchi T, Nakaoka D, Kanzawa M, Yano S, Ozuru R, Sugishita T, Chihara K. Plasma leptin concentrations are associated with bone mineral density and the presence of vertebral fractures in postmenopausal women. Clin Endocrinol (Oxf). 2001 Sep;55(3):341-7.

16. Morberg CM, Tetens I, Black E, Toubro S, Soerensen TI, Pedersen O, Astrup A. Leptin and bone mineral density: a cross-sectional study in obese and nonobese men. J Clin Endocrinol Metab. 2003 Dec;88(12):5795800 .

17. Małyszko J, Małyszko JS, Bondyra Z, Wołczyński S, Łebkowska U, Myśliwiec M. Bone mineral density and bone metabolism are not related to leptin in hemodialyzed and peritoneally dialyzed uremic patients. Med Sci Monit. 2004 Jun;10 Suppl 3:115-9.

18. Mahdy KA, Ahmed HH, Mannaa F, Abdel-Shaheed A. Clinical benefits of biochemical markers of bone turnover in Egyptian children with chronic liver diseases. World J Gastroenterol. 2007 Feb 7;13(5):785-90.

19. Shenouda M, EI-Zein M, Sharaf-El-Din M, El-Esper I, Boitte F, Fournier A, Barsoum R. Cirrhosis ameliorates renal osteodystrophy in patients on regular hemodialysis. Hemodialysis International. 2004 Jan;8(1):86-7.

20. Akhtar I, González EA. Biologic effects of parathyroid hormone metabolites: implications for renal bone disease. J Investig Med. 2004 Jan;52(1):51-7.

21. Zoccali C, Panuccio V, Tripepi G, Cutrupi S, Pizzini P, Mallamaci F. Leptin and biochemical markers of bone turnover in dialysis patients. J Nephrol. 2004 MarApr;17(2):253-60.

22. Schiefke I, Fach A, Wiedmann M, Aretin AV, Schenker E, Borte G, Wiese M, Moessner J. Reduced bone mineral density and altered bone turnover markers in patients with non-cirrhotic chronic hepatitis B or C infection. World J Gastroenterol. 2005 Mar 28;11(12):1843-7.

23. Briley LP, Szczech LA. Leptin and renal disease. Semin Dial. 2006 Jan-Feb;19(1):54-9.

24. Wiscek A. How does leptin contribute to uraemic cachexia? Nephrol Dial Transplant. 2005 Dec;20(12):2620-2.

25. Honda $H$, Ikejima $K$, Hirose $M$, Yoshikawa $M$, Lang T, Enomoto N, Kitamura T, Takei Y, Sato N. Leptin is required for fibrogenic responses induced by thioacetamide in the murine liver. Hepatology. 2002 Jul;36(1):12-21.
26. Uygun A, Kadayifci A, Yesilova Z, Erdil A, Yaman H, Saka M, Deveci MS, Bagci S, Gulsen M, Karaeren N, Dagalp K. Serum leptin levels in patients with nonalcoholic steatohepatitis. Am J Gastroenterol. 2000 Dec;95(12):3584-9.

27. Barnas U, Schmidt A, Seidl G, Kaider A, Pietschmann P, Mayer G. A comparison of quantitative computed tomography and dual X-ray absorptiometry for evaluation of bone mineral density in patients on chronic hemodialysis. Am J Kidney Dis. 2001 Jun;37(6):124752.

28. Goodman WG. Medical management of secondary hyperparathyroidism in chronic renal failure. Nephrol Dial Transplant. 2003 Jun;18 Suppl 3:iii2-8.

29. Ormarsdóttir S, Ljunggren O, Mallmin H, Michaëlsson $\mathrm{K}$, Lööf L. Increased rate of bone loss at the femoral neck in patients with chronic liver disease. Eur J Gastroenterol Hepatol. 2002 Jan;14(1):43-8.

30. Ghazali A, Grados F, Oprisiu R, Bunea D, Morinière P, El Esper N, El Esper I, Brazier M, Souberbielle JC, Fournier A, Thomas T. Bone mineral density directly correlates with elevated serum leptin in haemodialysis patients. Nephrol Dial Transplant. 2003 Sep;18(9):188290 .

31. Ormarsdóttir S, Ljunggren $\mathrm{O}$, Mallmin H, Olofsson $\mathrm{H}$, Blum WF, Lööf L. Inverse relationship between circulating levels of leptin and bone mineral density in chronic liver disease. J Gastroenterol Hepatol. 2001 Dec;16(12):1409-14.

32. Ducy P, Amling M, Takeda S, Priemel M, Schilling AF, Beil FT, Shen J, Vinson C, Rueger JM, Karsenty G. Leptin inhibits bone formation through a hypothalamic relay: a central control of bone mass. Cell. 2000 Jan 21;100(2):197-207.

33. Caro JF, Kolaczynski JW, Nyce MR, Ohannesian JP, Opentanova I, Goldman WH, Lynn RB, Zhang PL, Sinha MK, Considine RV. Decreased cerebrospinal-fluid/serum leptin ratio in obesity: a possible mechanism for leptin resistance. Lancet. 1996 Jul 20;348(9021):159-61.

34. Agras PI, Baskin E, Saatci U, Colak T, Cengiz N, Kinik ST, Isiklar I, Haberal A, Mert I, Haberal M. Relationship between leptin and bone mineral density in renal transplant recipients. Transplant Proc. 2005 Sep;37(7):3106-8.

35. Iwamoto I, Douchi T, Kosha S, Murakami M, Fujino $\mathrm{T}$, Nagata Y. Relationships between serum leptin level and regional bone mineral density, bone metabolic markers in healthy women. Acta Obstet Gynecol Scand. 2000 Dec;79(12):1060-4. 